\title{
Role of Training in Transferring Rice Production Technologies to Farm Level
}

M S Hossain ${ }^{*}$, A K M S Islam², M J Kabir ${ }^{3}$, M A R Sarkar ${ }^{3}$, M A A Mamun', M C Rahman³, M U Salam5 and M S Kabir ${ }^{6}$

\begin{abstract}
Farmers' knowledge gap in modern rice cultural practice is the main cause of the existing yield gap in Bangladesh. Thus, this paper delineates; (i) the level of farmers' knowledge gap; (ii) assesses the impact of training on changes in the farmers' skills, knowledge as well as technology adoption, and crop performance. Finally propose an approach for improving farmers' skills on modern rice cultural practices through fruitful training. Secondary data, in particular, journal articles were reviewed and analyzed in the paper. From the analysis, we found that majority of the farmers (85\%) belong to the medium level of the overall knowledge gap category. There was a significant increase in the knowledge and skills of farmers after undertaking the training. As a result, the rice yield of trained progressive farmers increased to $4.7 \mathrm{t} \mathrm{ha}^{-1}$ in 2012 from $3.1 \mathrm{t} \mathrm{ha}^{-1}$ in 2008 . However, the rice yield of ordinary trained farmers increased to $3.7 \mathrm{t} \mathrm{ha}^{-1}$ in 2012 from around $2.6 \mathrm{t} \mathrm{ha}^{-1}$ in 2008 . The traditional extension approach was less efficacious to improve farmers' knowledge gap and disseminate the rice production technologies to the farm level. Therefore, strengthening BRRI's capacity to provide seed to seed training to most of the DAE personnel to upgrade their skills on modern rice technologies is critically important. Besides, demonstrations based farmers training might be highly productive in transferring modern rice production technologies to the farmers.
\end{abstract}

Key words: Farmers' knowledge gap, rice yield gap, seed to seed training, training approach

\section{INTRODUCTION}

Training is a mode of transferring knowledge and skills and has been applying in the agelong for improving performance and responsibilities of skills and unskilled manpower (Adisa and Okunade, 1995). Similarly, reported that it is a highly effective approach for updating farmers' knowledge and disseminating modern technologies to farmers' fields for raising crop productivity (Ajayi, 2015). Department of Agriculture Extension (DAE) a public organization in Bangladesh, is the main body to disseminate the modern technologies and information developed by research organizations to the farmers. Although, private sectors, NGOs, and research organizations also the other forces of the technology transfer process. DAE introduces farmers to modern technologies of rice and non-rice crops through training, technology demonstration, field days, etc, and provides information to farmers about modern technologies. However, there was about a $20 \%$ rice yield gap (Kabir et al., 2015) and it is estimated as $20.68 \%$ (Kabir et al., 2020) in Bangladesh. For reducing the yield gap, it is critically important to (i) disseminate the higher yield potential rice cultivars and component technologies to farmers' fields as well as (ii) improve farmers' knowledge about the production technologies. To do so, several diffusion determinants of new technologies are used in extension approaches which are mentioned earlier. Among the major diffusion determinants of new technologies, knowledge spillover is considered one of the most important factors in technology dissemination (Munshi, 2004; Foster et al., 1985, Basely and Case, 1993).

Hence, training is considered one of the most effective tools to improve farmers' knowledge and skills in modern technologies.

\footnotetext{
${ }^{1}$ Training Division, Bangladesh Rice Research Institute (BRRI), Gazipur-1701, Bangladesh; ${ }^{2}$ Farm Machinery and Postharvest Technology Division, BRRI, Gazipur-1701, Bangladesh; ${ }^{3}$ Agricultural Economics Division, BRRI, Gazipur1701, Bangladesh; ${ }^{4}$ Agricultural Statistics Division, BRRI, Gazipur-1701, Bangladesh; ${ }^{5}$ Freelance International Consultant (Agricultural Systems), Bangladesh; ${ }^{6}$ Director General, BRRI, Gazipur-1701, Bangladesh.

*Corresponding author's E-mail: sahadatbrri@yahoo.com (M S Hossain)
} 
However, it was reported that most of the training programmes have so many weaknesses (Satter, 2012). As a result, it fails to upgrade farmers knowledge and skills up to the mark or desired level. Moreover, most of the DAE trainers have no training on modern rice cultural practices and agronomic management. Therefore, improvement of knowledge and skills of extension personnel and farmers on modern technologies of rice is required to disseminate the technologies to farmers' fields. Thus, the present study assessed(i) farmers' knowledge gap on the recommended practices of rice cultivation, (ii) the impact of training on the knowledge and adoption of technologies, and (iii) delineates a training model to reduce farmers' knowledge gap.

Followed by the introduction, it presents methodology, results and discussion, including farmers' knowledge gap on modern rice cultivation practices, the impact of training on knowledge and skills, and the impact of training on the adoption of technologies and yield. It is followed by current technology transfer approach and effectiveness of the BRRI training activities, a model for alleviating drawback of conventional training approach, training module and methods and future directions of BRRI training programme. This is followed by conclusions and recommendations.

\section{METHODOLOGY}

Relevant published journal articles were collected through google scholars and analyzed the key findings on the status of farmers' knowledge on modern cultural practices, the significance of training on farmers' skills, and the performance of rice crops. It indicates that mainly secondary data were used for the study. Besides, primary data on the significance of training and how to improve farmer's skills were collected through key informant's interviews with researchers and extension personnel.

\section{RESULTS AND DISCUSSION}

\section{Impact of training: earlier experiences}

\section{Farmers knowledge gap on modern rice cultivation practices.}

The data in Table 1 reveal that the majority of the rice farmers $(85 \%)$ belonged to the medium knowledge gap category with a mean technological gap score of 56.51, followed by $15 \%$ of total respondents belong to the low knowledge gap category with a mean technological gap score of 21.94. It is also evident from the data that none of the rice farmers belongs to the high knowledge gap category.

It was observed that there was a wide variation in the farmer's knowledge gap when it was measured based on key yield contributing factors like pest management, fertilizer management, harvest and post harvest management etc. It can be noted that farmers have the highest knowledge gap on pest management followed by fertilizer management and, harvest as well as postharvest management (Table 2).

Table 1. Classification of farmers based on knowledge gap.

\begin{tabular}{lcccc}
\hline Category & Frequency & Percent & Mean & SD \\
\hline Low knowledge gap (Up to 33\%) & 15 & 15 & 21.94 & 14.12 \\
Medium knowledge gap(34 to 84\%) & 85 & 85 & 56.51 & 16.96 \\
High knowledge gap (85\% and above) & 0 & 0.00 & 00.00 & 0.00 \\
Total & 100 & 100 & - & - \\
\hline
\end{tabular}

Note: The knowledge gap was measured based on the difference between the possible knowledge score for the 36 questions and the actual knowledge score, SD-Standard deviation. Source: Tengli and Sharma, 2017, p.1227 
Table 2. Farmers' knowledge gap on different yield contributing factors.

\begin{tabular}{lcc}
\hline Yield contributing factors & Knowledge gap & Rank \\
\hline Variety and its attributes & 151 & $6^{\text {th }}$ \\
Seedling age & 499 & $4^{\text {th }}$ \\
Time of transplanting and spacing & 470 & $5^{\text {th }}$ \\
Pest management & 900 & $1^{\text {th }}$ \\
Fertilizer management & 863 & $2^{\text {th }}$ \\
Harvest and post-harvest management & 734 & $3^{\text {rd }}$ \\
\hline
\end{tabular}

Note: The knowledge gap of the farmers is classified based on six yield contributing factors. It was estimated by deducting the obtained knowledge score from the possible knowledge score of the respondents under each factor. Adopted from Islam et al., 2018, p.3

\section{Impact of training on knowledge and skills}

Table 3 presents the rating of farmers' knowledge and skills on major yield contributing factors before and after undertaking training. Overall, positive changes have taken place in the farmer's skills on all the production techniques after training. The positive changes have taken place on farmers' knowledge on major yield contributing factors including variety, seedling age, time of transplanting and spacing, pest management, fertilizer management, harvest, and post-harvest management, and irrigation as well as water management.

\section{Impact of training on the adoption of technologies and yield}

Table 4 presents rice yield and level of adoption of major yield contributing factors by farm types from 2008 to 2012. It was observed that progressive farmers obtained a slightly higher yield $\left(0.5 \mathrm{t} \mathrm{ha}^{-1}\right)$ even before the training in 2008. Besides, there was no statistically significant yield difference between intermediary and ordinary farmers. However, per hectare rice yield of progressive farmers after training increased to $4.4 \mathrm{t} \mathrm{ha}^{-1}$ in 2009 from $3.1 \mathrm{t} \mathrm{ha}^{-1}$ in 2008 due to higher adoption of technologies. The adoption rate of modern technologies increased substantially since 2009 and continued to increase until 2012. As a result, progressive farmers obtained a significantly higher yield $\left(2 \mathrm{t} \mathrm{ha}^{-1}\right)$ than ordinary farmers from 2009 to 2011.

Table 3. Changes of knowledge and skills after the training.

\begin{tabular}{|c|c|c|c|c|c|c|c|c|}
\hline \multirow[t]{2}{*}{ Yield contributing aspect } & \multicolumn{4}{|c|}{ Knowledge (mean) } & \multicolumn{4}{|c|}{ Skill acquired (mean) } \\
\hline & $\begin{array}{l}\text { Before } \\
\text { training }\end{array}$ & $\begin{array}{l}\text { After } \\
\text { training }\end{array}$ & $\begin{array}{l}\text { Mean } \\
\text { diff }\end{array}$ & $\begin{array}{l}\mathrm{Z} \\
\text { value }\end{array}$ & $\begin{array}{l}\text { Before } \\
\text { training }\end{array}$ & $\begin{array}{l}\text { After } \\
\text { training }\end{array}$ & $\begin{array}{l}\text { Mean } \\
\text { diff }\end{array}$ & $\begin{array}{l}Z \\
\text { value }\end{array}$ \\
\hline Variety and its attributes & 2.68 & 4.06 & 1.38 & 1.68 & 1.68 & 4.10 & 2.42 & 3.21 \\
\hline Seedling age & 2.98 & 3.96 & 0.98 & 1.13 & 2.07 & 3.87 & 1.80 & 3.43 \\
\hline $\begin{array}{l}\text { Time of transplanting and } \\
\text { spacing }\end{array}$ & 1.67 & 3.00 & 1.33 & 1.62 & 2.06 & 4.21 & 2.15 & 4.46 \\
\hline Pest management & 1.38 & 3.87 & 2.49 & 2.00 & 1.40 & 3.53 & 2.13 & 1.74 \\
\hline Fertilizer management & 2.80 & 3.11 & 0.31 & 1.13 & 2.53 & 3.43 & 0.90 & 3.03 \\
\hline $\begin{array}{l}\text { Harvest and post-harvest } \\
\text { management }\end{array}$ & 1.86 & 2.70 & 0.84 & 0.32 & - & - & - & - \\
\hline $\begin{array}{l}\text { Irrigation and water } \\
\text { management }\end{array}$ & 1.92 & 3.17 & 1.25 & 1.86 & - & - & - & - \\
\hline
\end{tabular}

Note: Modified from Aphunu and Ajayi, 2010, p.135.Pre and post-test were done before and after training for each participant. Z-test was used to test the significant difference between knowledge and skills possessed before and after the training programme. 
Table 4. Rice yield and adoption of technologies by different farmers' types.

\begin{tabular}{|c|c|c|c|c|c|c|}
\hline \multirow{2}{*}{$\begin{array}{l}\text { Year and } \\
\text { sample } \\
\text { size }\end{array}$} & \multicolumn{6}{|c|}{ Progressive farmer } \\
\hline & Yield $\left(\right.$ tha $\left.^{-1}\right)$ & $\begin{array}{c}\text { Fertilizer } \\
\left(\text { kgha }^{-1}\right)\end{array}$ & $\begin{array}{c}\% \text { of used modern } \\
\text { varieties }\end{array}$ & $\begin{array}{l}\% \text { of plots with } \\
\text { improved bund }\end{array}$ & $\begin{array}{c}\% \text { of leveled } \\
\text { plots }\end{array}$ & $\begin{array}{c}\text { \%farmers } \\
\text { transplanted in rows }\end{array}$ \\
\hline $2008(n=13)$ & $3.1^{*}$ & 63.4 & $46.2^{*}$ & $15.4^{* *}$ & 46.2 & 23.1 \\
\hline $2009(n=13)$ & $4.4^{* * *}$ & $115.8^{* * *}$ & $69.2^{* * *}$ & $23.1^{* * *}$ & 76.9 & $76.9^{* * *}$ \\
\hline $2010(n=16)$ & $4.8^{* * *}$ & $137.7^{* * *}$ & $65.8^{* * *}$ & $31.3^{* * *}$ & 81.3 & $93.8^{* * *}$ \\
\hline $2011(n=14)$ & $5.3^{* * *}$ & $164.5^{* * *}$ & $54.8^{* * *}$ & $42.9^{* * *}$ & 85.7 & $92.9^{* * *}$ \\
\hline $2012(n=13)$ & $4.7^{* *}$ & $131.3^{* * *}$ & $66.7^{* * *}$ & 15.4 & 76.9 & $92.3^{* * *}$ \\
\hline \multicolumn{7}{|c|}{ Moderately progressive farmer } \\
\hline $2008(n=23)$ & 2.5 & $22.2^{* *}$ & 30.4 & $13.0^{*}$ & $43.5^{* *}$ & 13 \\
\hline 2009(n=27) & 2.6 & 49 & $44.4^{* *}$ & $18.5^{* * *}$ & 70.4 & $44.4^{* * *}$ \\
\hline $2010(n=31)$ & 2.8 & 79.1 & $40.8^{* *}$ & $22.6^{* * *}$ & 74.2 & $64.5^{* * *}$ \\
\hline $2011(n=24)$ & $4.6^{* * *}$ & $103.9^{*}$ & 34.4 & $33.3^{* *}$ & 79.2 & $45.8^{* *}$ \\
\hline $2012(n=24)$ & 3.9 & 95.2 & $49.5^{* *}$ & $33.3^{* * *}$ & 62.5 & $58.3^{* *}$ \\
\hline \multicolumn{7}{|c|}{ Ordinary farmer } \\
\hline $2008(n=135)$ & 2.6 & 46.5 & 26.7 & 3 & 54.8 & 11.1 \\
\hline $2009(n=142)$ & 2.7 & 58.3 & 26.8 & 4.9 & 64.1 & 19 \\
\hline $2010(n=155)$ & 2.5 & 69.7 & 25.7 & 7.7 & 69 & 25.8 \\
\hline $2011(n=130)$ & 3.6 & 85.8 & 23.6 & 16.2 & 76.2 & 26.9 \\
\hline $2012(\mathrm{n}=130)$ & 3.7 & 83.2 & 32.9 & 11.5 & 66.9 & 36.9 \\
\hline
\end{tabular}

Source: Adopted from Yuko Nakano et al. 2018, p. 25. Note: *, ** and *** indicate level of significance at the 1\%, 5\% and 10\% level

As soon as after receiving training in 2009, intermediary farmers also improved their rice production practices through adopting modern cultural practices. Which resulted to get them increased yield $\left(4.6 \mathrm{t} \mathrm{ha}^{-1}\right)$ in 2011 compared to $2008\left(2.5 \mathrm{t} \mathrm{ha}^{-1}\right)$. It was observed that the rate of rice yield increased for intermediary farmers was lower than progressive farmers, and rice yield difference between ordinary and intermediary farmers was only significant in 2011.

From the above discussion, it can be claimed that an effective mode of training is highly efficacious to increase farmers' knowledge and skills; consequently, farm productivity might increase because of the rising adoption of modern technologies and improving agronomic management.

\section{Current Technology Transfer Approach}

The public and private sectors, including NGOs, research organizations as well as farmers play a pivotal role to transfer technologies and knowledge to the end-users for enhancing the production of agriculture crops, livestock, and aquaculture. DAE has been contributing most to disseminating technologies to the farmers' fields as it is mainly mandated to disseminate the modern agriculture technologies and information to the farmers' field through training and others extension methods. Figure 1 presents the approaches of disseminating the National Agriculture Research System (NARS) developed modern agricultural technologies through DAE. It was observed that NARS organizations developed higher yield potential cultivars and component technologies for agronomic, biotic, and abiotic stress management of crops. Thereafter, the NARS organizations provide training on modern cultural practices to extension and other development personnel for disseminating the technologies to farmers' fields. In this process of disseminating technologies to the farm level, the upazila level and field level (i.e., Sub Assistant Agriculture Officer) agriculture extension personnel play a vital role to make the farmers adopt the technology. Therefore, they need to acquire the latest technical information innovated by the research organizations. So that they can perform their job effectively. 


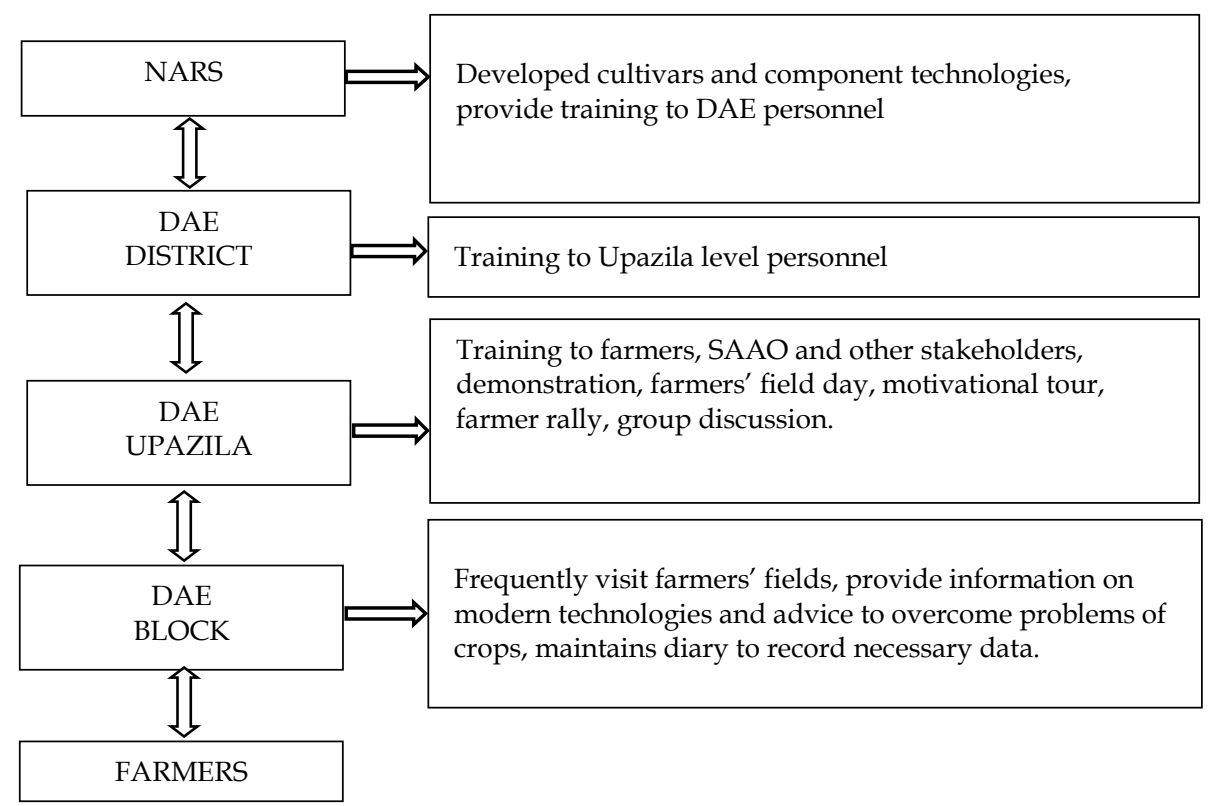

Fig. 1. Information flow during technology dissemination of DAE (Adopted from Satter, 2012).Note: Department of Agriculture Extension (DAE), National Agriculture Research System (NARS), Sub-assistant Agriculture officer (SAAO)

BRRI is not only a pioneer in developing higher yield potential rice cultivars and component technologies but also provides short and long-term training to DAE personnel disseminating the cultivars and technologies to farm level. The trainees may contribute directly through providing training to farmers and indirectly through providing training to trainers for disseminating the technologies for enhancing rice production. In total, BRRI has given training to 34,332 extension personnel since its establishment.

\section{Effectiveness of the BRRI training}

As mentioned above that BRRI has given training to 34,332 extension personnel since its establishment. Table 5 presents the performance of trainees trained by BRRI. It was observed that the mean score of preevaluation of extension personnel on modern rice cultural practice was $26 \%$, indicating that there was about a three-fourths gap in their knowledge on rice technologies. However, the mean post-evaluation score of the trainees was $76 \%$, indicating that the knowledge gap reduced to one-fourth from three-fourths. It was also the case that the post-evaluation score of $95 \%$ of total trainees was 86 , which implies that the training provided by BRRI was highly potential to improve trainees' knowledge. In short, results of the quantitative evaluation suggest the training programme was highly successful and well-received by the participants.

Table 5. Distribution of respondents according to their knowledge scores.

\begin{tabular}{|c|c|c|c|c|c|c|}
\hline \multirow{2}{*}{ Category } & \multicolumn{3}{|l|}{ Pre training } & \multicolumn{3}{|l|}{ Post training } \\
\hline & Trainee (\%) & Score & Mean score & Trainee (\%) & Score & Mean score \\
\hline Low knowledge $(<60)$ & 98 & 28 & & 0 & 0 & \\
\hline Medium knowledge(60-79) & 2 & 61 & 26 & 5 & 76 & 76 \\
\hline High knowledge (> 80) & 0 & 0 & & 95 & 86 & \\
\hline Total & 100 & & & 100 & & \\
\hline
\end{tabular}

Note: Achievement was measured from difference between mean of post-training and mean of pre-training. 
Despite such joint effort of NARS and DAE, still, there is over $20 \%$ of rice yield gap in Bangladesh (Kabir et. al., 2015). Which is one of the key barrier on the way to achieving the food security challenges for 2030.

Now the question is, why the yield gap occurs? Firstly, farmers are not being able to adopt modern cultural management practices. Because with an exception to a few, training provided to farmers on rice productions neither demand-driven nor its curricula are modern and consistent with farmers' needs. Besides, it is a one-way deliberation in a classroom by the speaker, so that farmers usually have few scopes for participation. Furthermore, the same farmers are invited for most training, and some of them are not solely farmers (farming is their secondary occupation) so that they are not fully concentrated on the talk and subject matters of the training (Satter, 2012). Secondly, there is a gap in the adoption of recommended management practices, consequently, about $15 \%$ of yield loss has occurred because of poor agronomic management (Kabir et al., 2020).

\section{Model for alleviating drawback of conventional training approach}

Figure 2 presents a new model to improve farmers' knowledge through alleviating the limitations of the conventional farmers' training method. The model delineates the roles of each collaborator and impacts the models on farmers' performance, rice yield, income, and livelihoods.

\section{Roles of different collaborators}

BRRI Training Division is a vital collaborator to provide training to the DAE personnel. BRRI should provide training to upazila level extension personnel to develop master trainers on rice production, and they will serve as master trainers to provide training to field level extension personnel and progressive farmers. Upazila level DAE personnel are one of the key collaborators; every upazila level agriculture office should be the main center of resources for disseminating technologies to farmers through training and other technology disseminating methods.

The field-level agriculture extension personnel i.e., SAAO is responsible for identifying the local need for training and selecting farmers through discussion with the key informant farmers including village leaders, imam of the mosque, and school teachers. The school teachers and fertilizer traders will also be invited to the training with progressive farmers. The upazila level extension personnel will provide training to farmers. There will be a training evaluation team that will monitor and assess the training programme as an independent third party looking to verify the effectiveness of the training programme.

\section{Training module and methods}

A rice production training module needs to be developed. It will cover a wide range of topics including rice variety and seed, agronomic management, pest management, fertilizer and irrigation management, post-harvest technology, and safe use of agrochemicals.

A group of 15-20 farmers consisting of an adult male and female member irrespective of farm size will be selected. The progressive farmers, school teachers, seed, and fertilizer traders also are trained as some farmers frequently ask for suggestions on fertilizers and pesticide application in rice crops from them.

Secondly, the DAE personnel will go to the village for providing training, and the training will be arranged at the farm household. It will be an informal training with two-way deliberation through question and answer. In addition to the lecture, some demonstrations will be set in the farmers' fields to provide hands-on training to the selected farm family members. The trained farmers will be encouraged to share knowledge with the neighbouring farmers and relatives in the community. 


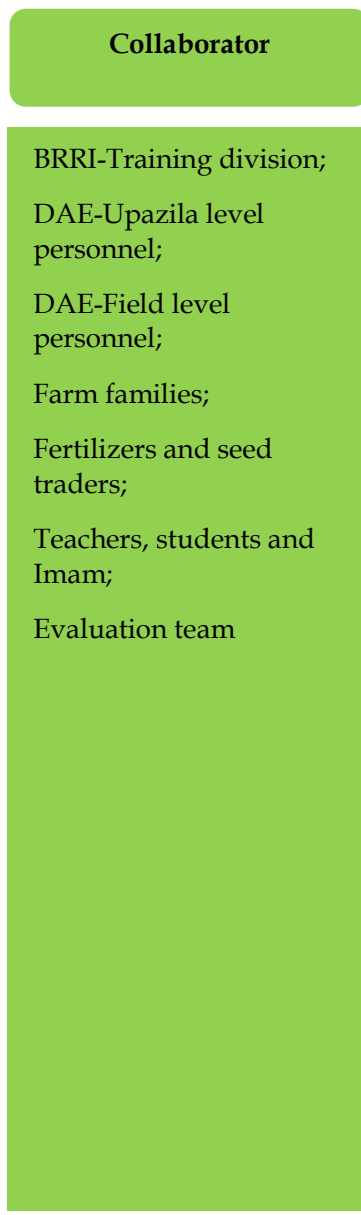

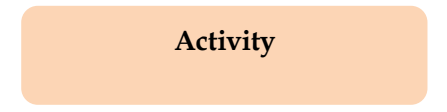

Select a male and female member of a family;

Provide an informal two-way training at village;

Set some field demonstrations;

Encourage farmers to share the knowledge with others;

Arrange training for teachers, traders and students;

Field level DAE staff visit farmers' fields and households to share knowledge and provide suggestion.

Form a farmers' club at village;

Encourage participant farmers to provide training to other farmers at the club;

Community meeting for knowledge sharing through information discussion.

\section{Impact}

Improve farmers' knowledge and reduce knowledge gap;

Improve adoption of modern cultivars and technologies;

Decrease over and under use of scarce resources;

Decrease yield gap and increase yield;

Increase farm income and improved farmers' livelihoods.

Fig. 2. Propose farmers training models (Developed based on Croplife Int. Aisbl, 2013).

Thirdly, a farmers' club will be constructed in each village under the core programme of government consisting of all farmers where trained farmers will meet with non-training farmers to share acquired knowledge to improve community performance.

Finally, the master trainers will give a lecture to students in the village level secondary school and madrasa (religious school) to improve their knowledge on modern rice production technologies as most of the students came from the farm families and participated in the farming activities.

\section{Impact of training module}

Both the participant and non-participant farmers' knowledge gap will be reduced after such a compressive approach of training at the village level. As a result, the adoption of modern technologies including cultivars, agronomic management, pest and water management will be increased. Not only the judicious use of scarce resources (land, labor, water, seeds, fertilizers, and pesticides) will be ensured but also the performance of the rice crop will be improved. Besides, the yield gap will be decreased, and farmers' livelihood will be improved because of increasing income due to increased yield and decreased cost for the judicious application of resources. 


\section{BRRI training programme: Future directions}

Table 6 presents anticipated training needs for disseminating rice technologies to farmers' fields in Bangladesh until 2050. Firstly, the training aims to develop the knowladge and skills of entry and mid-level rice researchers to harvest their full potential in the development and dissemination of rice technologies. Secondly, the proposed training is aimed to update the knowledge and skills of field-level extension personnel including Sub-assistant Agriculture Officer (SAAO), Agriculture Extension Officer (AEO), and Additional Agriculture Officer (AAO) to disseminating the knowledge to root level farmers. The focus of the training is to develop master trainers on modern rice production practices to provide training to farmers. It can be noted that farmers' knowledge and skills on major yield contributing factors of rice have positively changed after training (Table 3). Besides, per hectare rice yield of progressive farmers increased to $4.4 \mathrm{t} \mathrm{ha}^{-1}$ in 2009 from $3.1 \mathrm{tha}^{-1}$ in 2008 after training. Similarly, in case of intermediary farmers it increased to $4.6 \mathrm{t} \mathrm{ha}^{-1}$ in 2011 from $2.5 \mathrm{t} \mathrm{ha}^{-1}$ in 2008 after training (Table 4). The results indicate that training has a substantial impact to reduce farmers' knowledge gap, consequently reduced the yield gap. Besides, BRRI Training Division has been set a target to provide an adequate number of skilled researchers and extension personnel to address the goal.

Table 6. Training for disseminating rice technologies to farmers' field under future conditions in Bangladesh.

\begin{tabular}{|c|c|c|c|c|c|c|}
\hline \multirow[t]{2}{*}{ Aim } & \multirow{2}{*}{$\begin{array}{l}\text { Training theme } \\
\text { / title }\end{array}$} & \multirow[b]{2}{*}{ Participant } & \multirow{2}{*}{$\begin{array}{l}\text { Duration } \\
\text { (week) }\end{array}$} & \multicolumn{3}{|c|}{ Year } \\
\hline & & & & $\begin{array}{l}2021- \\
2030\end{array}$ & $\begin{array}{l}2031- \\
2040\end{array}$ & $\begin{array}{l}2041- \\
2050\end{array}$ \\
\hline \multirow[t]{7}{*}{ Capacity buildup } & $\begin{array}{l}\text { Modern rice } \\
\text { production }\end{array}$ & \multirow{7}{*}{ Scientist } & 8 & 120 & 150 & 200 \\
\hline & $\begin{array}{l}\text { Molecular } \\
\text { technology }\end{array}$ & & 8 & 150 & 200 & 200 \\
\hline & $\begin{array}{l}\text { Writing journal } \\
\text { articles }\end{array}$ & & 1 & 500 & 500 & 500 \\
\hline & Bioinformatics & & 1 & 120 & 120 & 120 \\
\hline & Communication skill & & 1 & 200 & 230 & 250 \\
\hline & $\begin{array}{l}\text { Research } \\
\text { methodology }\end{array}$ & & 1 & 400 & 400 & 400 \\
\hline & Writing PP & & 1 & 400 & 400 & 400 \\
\hline Capacity buildup & $\begin{array}{l}\text { Modern rice production and data } \\
\text { collection methods }\end{array}$ & SA & 1 & 120 & 120 & 120 \\
\hline \multirow{3}{*}{$\begin{array}{l}\text { Technology } \\
\text { dissemination }\end{array}$} & Modern rice production & & 4 & 1,200 & 1,200 & 1,200 \\
\hline & $\begin{array}{l}\text { Rice pest, agronomic \& irrigation } \\
\text { management }\end{array}$ & $\mathrm{AEO} / \mathrm{AAO}$ & 1 & 1,500 & 1,500 & 1,500 \\
\hline & $\begin{array}{l}\text { Hybrid seed } \\
\text { production }\end{array}$ & & 1 & 1,500 & 1,500 & 1,500 \\
\hline \multirow[t]{2}{*}{$\begin{array}{l}\text { Technology } \\
\text { dissemination }\end{array}$} & $\begin{array}{l}\text { Modern rice } \\
\text { production }\end{array}$ & SAAO & 1 & 7,000 & 8,000 & 10,000 \\
\hline & Farmers' fields day & $\begin{array}{l}\text { Farmers/ } \\
\text { Traders/ } \\
\text { Teacher/ } \\
\text { Imam }\end{array}$ & 0.7 & 80,000 & 100,000 & 120,000 \\
\hline $\begin{array}{l}\text { Updating } \\
\text { policy level }\end{array}$ & $\begin{array}{l}\text { Cutting edge } \\
\text { BRRI technology } \\
\text { appraisal }\end{array}$ & $\begin{array}{l}\text { Senior } \\
\text { management }\end{array}$ & 0.7 & 5 & 5 & 5 \\
\hline
\end{tabular}

SA $=$ Scientific Assistant, $\mathrm{PP}=$ Project Proposal, Senior Management-Public and Private Organization 


\section{CONCLUSION}

Farmers' lack of knowledge is the main reason for high yield gap in Bangladesh, despite strenuous efforts of public and private sectors including NGOs. Training facilitates improve farmers' knowledge and skills, signaficantly and increased adoption of recommended technologies, consequently increased yield and farm income. However, the conventional approach of training has some limitations to improve farmers' knowledge up to the mark. Therefore, a model is proposed to provide effective training to farmers through the collaboration of researcher, extension, and community level. Besides, capacity of the Training Division and BRRI scientists needs to be strengthened to provide seed to seed rice production training to the DAE personnel for upgrading their capacity on modern rice technologies. Moreover, demonstration-based farmers' training might be highly productive in transferring modern rice production technologies to the farmers. Finally, policy supports are needed for implementing proposed future directions of training needs for dissemination of rice technologies to the farmers' fields.

\section{RECOMMENDATIONS}

The policy supports are essential for strengthening (i) BRRI's capacity to provide hands-on training to most of the DAE's personnel for enhancing their skills on modern rice production practice and (ii) DAE capacity to provide whole family seed to seed rice production training through technology demonstration at farmers' fields in each DAE block to alleviate farmers' knowledge gap for achieving the full potential of the rice cultivars for sustainable rice production.

\section{ACKNOWLEDGEMENTS}

The authors wish to thank anonymous reviewers for their suggestions, which significantly improved this article.

\section{AUTHORS' CONTRIBUTION}

MSH, MUS, and MSK generated idea; AKMSI, MARS andMAAM coordinated the research; MSH and MJK developed methodology; MSH, MJK, MARS, MUS and MSK provided scientific insights; MSH gathered data, carried out analysis and synthesis; MSH and MJK did the writings for all versions of the manuscript; MUS, AKMSI, MARS, MCR and MAAM performed critical review and editing; All authors read and approved the final manuscript.

\section{DECLARATION OF INTERESTS}

A version of the paper was published in a book Doubling Rice Productivity in Bangladesh in 2020 by the Bangladesh Rice Research Institute (BRRI), Gazipur 1701, Bangladesh to commemorate BRRI's 50 th anniversary. The Bangladesh Rice Journal has prior knowledge of the book publication and does not see any conflict of interest.

\section{REFERENCES}

Adisa, B O and E O Okunade. 2005. Women in agriculture and rural development. In: Adedoyin, SF (ed). Agriculture Extension in Nigeria. Agriculture Extension Society of Nigeria (AESON), Ilorin: 69-77.

Ajayi, M T. 2005. Impact of training on level of adoption of improved practices among Cassava farmers in Southwestern Nigeria. International Journal of Agriculture and Rural Development, 6: 34-38.

Aphunu, A and M T Ajayi. 2010. Assessment of farmers' perception on the effectiveness of songhi delta fish culture training programme in delta state, Nigeria. J. of Tropical Agril., Food, Environment and Extension, 9 (2): 131-136.

Basele, T and A Case. 1993. Modeling technology adoption in developing countries. American Economic Review, 83 (2): 396-402.

BBS (Bangladesh Bureau of Statistics). 2017. Statistical Yearbook of Bangladesh, Bangladesh Bureau of Statistics $(B B S)$, Statistics Division, Ministry of Planning, Government of the People's Republic of Bangladesh.

Croplife International. 2013. Training Through Local Partnerships: A model for agricultural training in rural farming communities. Project Booklets. 326 Avenue Louise, Box 35, 1050 Brussels, Belgium

Training for Technology Transfer 119 
Fester, G, R E Justand D Zilberman. 1985. Adoption of agriculture innovations in developing countries: A survey. Economic Development and Cultural Change, 33: $255-98$

Islam, M A, M E M Chowdhury and S D Baishakhy. 2018. Knowledge gap of the haor farmers in Boro rice cultivation. Asian Research Journal of Arts and Social science, 6 (3): 1-8.

Kabir, M S, M U Salam, A Chowdhury, N M F Rahman, K M Iftekharuddaula, M S Rahman, M H Rashid, S S Dipti, A Islam, M A Latif, A K M S Islam, M M Hossain, B Nessa, T H Ansari, M A Ali and J K Biswas. 2015. Rice Vision for Bangladesh: 2050 and Beyond. Bangladesh Rice J., 19 (2): 1-18.

Kabir, M S, M U Salam, A K M S Islam, M A R Sarkar, M A A Mamun, M C Rahman, B Nessa, M J Kabir, H B Shozib, M B Hossain, A Chowdhury, M Nasim, K M Iftekharuddaula, M S Hossain, M K A Bhuiyan, B Karmakar, M S Rahman, M M Haque, M T Khatun, M P Ali, S M H A Rabbi, P L Biswas, E S M H Rashid and N M F Rahman. 2020: Doubling rice productivity in Bangladesh: A way to achieving SDG2 and moving forward. Bangladesh Rice Journal, 24 (2): 1-47.

Munshi, K. 2004. Social learning in a heterogeneous population: Technology diffusion in the Indian green revolution. Journal of Development Economics, 73 (1): 185-213.

Nakano, Y, Y Tanaka and K Otsuka. 2018. Impact of training on the intensification of rice farming: evidence from rainfed areas in Tanzania. Agriculture Economics, 49: 193-202.

Satter, S A. 2012. Agriculture extension for Bangladesh based on field experience. Bangladesh Journal of Extension Education, 24 (1 and 2): 89-97.

Tengli, M B and O P Sharma. 2017. Technological gap in adoption of improved paddy cultivation practices. International Journal of current Microbiology and Applied Sciences, 6 (11): 1224-1229. 